\title{
Un Quijote alemán en la selva: Max Schmidt en el Mato Grosso y en el Chaco
}

Bossert, Federico \& Villar, Diego. Hijos de la selva/Sons of the Forest: La fotografía etnográfica de Max Schmidt/The Ethnographic Photography of Max Schmidt. Edición de Viggo Mortensen, versión bilingüe español/ inglés, Santa Mónica/California, Perceval Press, 2013, 136 pp.

Rodrigo Montani

Conicet, Argentina

La portada del libro es el espléndido retrato, tomado en la misión de Esteros en el año 1935, de un anciano nivaclé con todo su atuendo cotidiano, mirando fijamente a la cámara. Adentro encontramos un pequeño prefacio del editor, un extenso, erudito y conmovedor estudio preliminar redactado por los autores, y casi una centena de imágenes etnográficas fascinantes sobre indígenas del Alto Xingú, del Mato Grosso, del Pantanal y del Chaco paraguayo, obtenidas entre 1910 y 1935. Cierra el volumen, como contraportada, la foto de una casa de los paresís de Utiarití, tomada entre 1927 y 1928, sobre la que se proyectan las sombras de algunos espectadores y del fotógrafo. He aquí un resumen mezquino de este libro-objeto, cuya meta es dar a conocer las fotos del insigne, aunque bastante olvidado, americanista alemán Max Schmidt (1874-1950). Hay que reconocer que, teniendo en mente al menos la región del Gran Chaco, las buenas fotos etnográficas antiguas, aunque no abundan, tampoco faltan - piénsese en un Erland Nordenskiöld o en un Guido Boggiani, por citar dos estilos disímiles -; sin embargo, hay algo realmente excepcional en las fotografías de Schmidt, en la figura 
REVISTA DE ANTROPOLOGIA, SÃO PAULO, USP, $20 \mathrm{I}$, V. $58 \mathrm{~N}^{\mathrm{O}} \mathrm{I}$.

de Schmidt como antropólogo y en este libro, y es por eso que estas tres cuestiones ameritan algunos comentarios.

Los autores y el editor han buscado deliberadamente que Hijos de la selva/Sons of the Forest "tenga un valor tanto académico como artístico" y, para conseguirlo, seleccionaron las mejores fotografías de Max Schmidt que se conservan en el Museo Etnográfico Andrés Barbero de la ciudad de Asunción - la institución que el etnólogo alemán ayudó a formar y dirigió durante los últimos veinte años de su vida. Preparados originalmente sobre placas de vidrio por el propio Schmidt, los negativos fueron transportados por el editor Viggo Mortensen a los Estados Unidos, donde un equipo de especialistas se encargó de copiarlos al formato digital con la mejor tecnología y la mayor resolución posible. Por su parte, Diego Villar y Federico Bossert redactaron una introducción que contextualiza las fotos en la biografía del sabio alemán e ilumina su vida y su obra con las circunstancias académicas, sociales, culturales y políticas que al antropólogo-fotógrafo le tocó discurrir.

Como señalan los autores, Max Schmidt escribió una obra "compuesta por lo general de análisis puntuales o comparativos de determinados aspectos de la lengua, la cultura material o las tecnologías indígenas basados en sus propias observaciones de campo y en [el estudio de] colecciones [de museos]" así como por "cientos de páginas de relatos de viaje" (p. 2)1 , y manifestó un "singular empeño por fotografiar, aún en las circunstancias menos favorables, la vida indígena" (p. 42). En el agudo estudio introductorio, Villar y Bossert repasan esta vida y esta obra a fin de reconstituir lo más plenamente posible el contexto que permite entender las fotografías del libro. La primera sección del ensayo está dedicada a la formación de Schmidt en Alemania, en la cual sobresale la influencia de la tradición etnológica relativista y empirista que recibió por parte de un linaje discipular que va de Alexander 
REVISTA DE ANTROPOLOGIA, SÃO PAULO, USP, $20 \mathrm{I} 5$, V. 58 No I.

von Humboldt a Karl von den Steinen, pasando por Adolf Bastian. Además, Villar y Bossert revisan la influencia más bien moderada - y atemperada por un espíritu crítico - que tuvieron sobre Schmidt la antropogeografía de Friedrich Ratzel y el naciente difusionismo de habla germana, y cómo sus reservas para con estas escuelas implicaron para Schmidt cierto relegamiento en la vida académica berlinesa. La segunda sección del estudio está dedicada a las expediciones del joven Schmidt a "los hijos de las selvas" y a sus trabajos en Berlín entre estos viajes. En primer lugar, la terriblemente accidentada excursión al Alto Xingú, con sus trágicas aventuras entre los bacairís, los nahukuás y los awetis (1900-1901), que un aventurero y romántico Schmidt logra sortear con una saludable cuota de humor. En segundo lugar, la experiencia bastante más feliz entre los guatós del Pantanal y los paresís de Mato Grosso (1901 y 1910). En tercer lugar, la redacción en Berlín de su tesis doctoral - un trabajo comparativo sobre los pueblos de la familia lingüística arawak - así como los años dedicados a un análisis de corte más teórico orientado hacia una "economía política", que parece anticipar los problemas de los "institucionalistas" en la antropología económica moderna y adquiere renovada vigencia en una antropología contemporánea que ha recobrado el interés por los estudios de la cultura material. Finalmente, "el último viaje al Mato Grosso" (1927-1928), en el cual Schmidt vuelve a visitar a los bakairís y a los paresís, logra trabajar con algunos kayabis y realiza un trabajo etnográfico pionero entre los umotinas. En la última sección del ensayo preliminar, Villar y Bossert indagan las circunstancias que llevaron a Schmidt a abandonar Alemania en 1929 e instalarse en Asunción, reseñan la expedición etnográfica que realizó al Chaco paraguayo inmediatamente concluida la sangrienta Guerra del Chaco (1932-1935), presentan un balance de la etnografía y la fotografía de Schmidt y, finalmente, nos ofrecen una noticia serena y emotiva de su muerte en Asunción. 
REVISTA DE ANTROPOlOGIA, SÃo PAULO, USP, $20 \mathrm{I} 5$, V. $58 \mathrm{~N}^{\circ} \mathrm{I}$.

Podría decirse que este ensayo vale más que lo que los autores declaran, porque es en realidad un estudio crítico de una figura y de un período clave para la americanística alemana. Sin embargo, prefiero ver en el texto el retrato diáfano, por momentos cómico o melancólico, pero siempre estimulante y ennoblecedor, de lo que sin duda fue una sola cosa: la persona, el investigador, el fotógrafo; un hombre jovial y romántico que viajaba sin demasiado equipaje y sin escolta, "la extrańa conjugación [...] entre un espíritu aventurero y un 'tímido ratón de biblioteca'" (p. 44), un defensor de la unidad psíquica humana, "un empirista acérrimo" (p. 42) y preanuncio de la metodología moderna de trabajo de campo; un trabajador incansable, estoico, hasta quijotesco, que de alguna forma, pese a todas sus desventuras, termina siendo admirable.

Como anticipa el subtítulo, este libro muestra en todo su esplendor "la fotografía etnográfica de Max Schmidt". Se trata de fotos excepcionales no sólo por la excelente calidad de la técnica o la exquisita composición de muchas tomas, sino también por la poética y la política que implican. Pongamos tan sólo dos ejemplos. En un caso, la foto, ese espejo detenido en el tiempo, refleja - sobre un fondo de selva - la imagen limpia de un hombre guató que empuja con el botador su canoa monóxila cargada con varas y su perro; el río también los refleja, mientras todos - incluido el fotógrafo -, sin mirarse directamente pero sabiendo de la existencia de los demás, lentamente siguen fluyendo. En otra fotografía, se ve una superposición impresionante de escenas complejas que se evocan mutuamente y se esfuman con la distancia: en primer plano, ocupando la derecha y el centro del cuadro, el techo de paja y las paredes de cańa y adobe de una choza chiriguana, un conjunto de siete imponentes vasijas volcadas, lonjas de cuero, tablas, varillas, chalas descartadas de algún choclo; a la izquierda, en segundo plano, un niño de pie, con pantalones, poncho y sombrero, mira al fotógrafo; 
REVISTA DE ANTROPOLOGIA, SÃO PAULO, USP, $20 \mathrm{I} 5$, V. 58 No I.

atrás, también mirando, aparecen más difusas las figuras de una niña con poncho y una mujer con vestido, que sostiene el largo pisón dentro de un gran mortero; por último, no muy lejos, se ve otra casa y otro patio que sirven de fondo borroso.

Como señalan los autores del libro, Max Schmidt fotografió individuos y grupos de personas, artefactos y lugares "como una forma de registro científico" (p. 42); un registro de detalle, originalidad y calidad indiscutible, en parte, probablemente, por responder a una concepción de la ciencia antropológica signada por el historicismo, el empirismo y el individualismo metodológico. Por otro lado, no cabe duda de que Schmidt tomó también estas fotos teniendo otras inquietudes. ¿Artísticas? Probablemente. Aunque quizá convenga ceñirse a lo que sabemos gracias a este nuevo libro: que a Schmidt más de una vez los grabados de su maestro von den Steinen y luego sus propias fotos le sirvieron como una suerte de "pasaporte" para que los indígenas le permitiesen realizar trabajo de campo, o bien que tomar las fotografías le requería parlamentar largamente con los indígenas, explicarles sus fines y persuadirlos. En la textura de una vasija, en la agitación del umotina Kodonepa que no cede a estarse quieto ante la cámara, en los gestos recios, en las sonrisas y en la sombra o la figura del propio fotógrafo, antes que el resultado de un ánimo esteticista, se percibe la clave compleja, bella y sutil en la que Schmidt optó por cifrar su búsqueda y su encuentro con los hijos de la selva.

Buscando al Hombre en la diversidad de los hombres, el etnólogo se apasionó por Sudamérica: leyó, reflexionó, viajó, observó, escuchó, juntó piezas, anotó palabras, cargó una pesada cámara y sacó muchísimas fotos. Sin embargo, podría pensarse que una ironía del tiempo le deparó al Schmidt fotógrafo un destino semejante al que tuvieron sus compañeros indígenas: se volvió objeto. Por eso es atractivo ver en este libro, al fin y al cabo un nuevo artefacto, la labor de manos amables que 
REVISTA DE ANTROPOLOGIA, SÃO PAULO, USP, $20 \mathrm{I}$, V. $58 \mathrm{~N}^{\mathrm{O}} \mathrm{I}$.

mucho tiempo después, en otro lugar, trataron al Schmidt-objeto con la misma pasión y respeto que él trató a los kayabis, a los chiriguanos, a los guatós o a los umotinas, para poner de manifiesto la parte del Hombre que hay en ellos y compartirlo con todos los hombres.

\section{Notas}

1 Todas las citas pertenecen a la obra que se reseña. 